\title{
IMPROVING KNOWLEDGE TRANSFER IN SIMULATION GAMES BASED ON COGNITIVE LOAD THEORY
}

\author{
Christian Ploder, Thomas Dilger, \& Reinhard Bernsteiner \\ Management Communication \& IT, MCI, Innsbruck (Austria)
}

\begin{abstract}
The aim of this paper is to develop a framework for case study teaching with the combined measurement of the student's cognitive load supporting by an integrated learning management system. Therefore, the authors have implemented some pre-studies and collected lots of experience before establishing this particular, on literature-based, framework how the case-based teaching could be transferred to a new digitalization level. The motivation therefore is based on the lecture topics of the authors and the curricula they are teaching in bachelor and master classes. All necessary theoretical background information as well as the in details explained framework of how to implement the correct setting is explained in this paper.
\end{abstract}

Keywords: Simulation game, case study teaching, cognitive load.

\section{Introduction}

One known challenge in teaching process management/quality management and governance in a master class of business informatics students is the abstractness of the topic, especially for students who do not have any practical experience. Therefore, the authors decided to implement some gamification aspects for planning and executing a simulation game. Students are more willing to engage within this setting to learn, further on have a higher satisfaction rate, and the knowledge transfer is more sustained. The benefits of this learning setting are apparent.

A further step would be to find out more about the perceived stress levels of the students during the process of knowledge transfer. There is one theory standing out to get more insights about the perceived stress level: the theory of cognitive load (Hart, 1986). This paper presents a possible framework of how cognitive load measurement could be implemented to gain more in-depth knowledge of the student's situation. First of all, the unique situation in our information systems courses is displayed in more detail by the layer concept shown in table 1 . In section 2 all theoretical backgrounds about cognitive load theory and knowledge transfer are mentioned. The methodology used and the results gained from the study are explained in section 3 followed by the framework in section 4 . Section 5 closes the paper with showing up the limitations of this work and giving an outlook in section 5.

Business informatics students have to deal with all the interfaces and information flows in the whole stack which is mentioned in table 1 to be able to learn about the challenges of system architects which is one of the skill levels they need. Students have to understand all the requirements given from the external perspective (layer 6) and break them down to the shop floor (layer 1) based on the integrated process view but also the supporting software systems has to be taken into consideration. To reach this level of integrated thinking and knowledge at the students, the authors aim for case study design with the integration of gamification aspects.

Table 1. Layer Concept for Simulation Game.

\begin{tabular}{clc}
\hline Layer & \multicolumn{1}{c}{ Layer Name } & Integrated \\
\hline 6 & $\begin{array}{l}\text { Governments and } \\
\text { External Authorities }\end{array}$ & \\
\hline 5 & Enterprise Governance & \\
\hline 4 & Data Analytics Layer & \\
3 & $\begin{array}{l}\text { ERP System Layer and } \\
\text { Process Management }\end{array}$ & \\
2 & Manufacturing Execution \\
& Layer & Shop Floor Layer
\end{tabular}


There are two different groups of students identified in the author's classes: (1) students with experience in corporations regulated by any quality norm with governance processes in place and (2) students without any practical experience or in companies without any quality management norm. The idea of the authors was first to measure the different levels of the cognitive load for every group and every student individually. Later on, deliver the prepared materials (seen as small knowledge transfer nuggets) to ensure, that every student can follow them on his own speed. In parallel, the level which is to reach for the whole class has to be set and further material for the fast lane students has to be provided. The measurement of the cognitive load is not trivial. This paper will give an idea of how it could look like for a group of 35 master students at MCI divided into two groups and afterward compare the results of the two groups.

\section{Theoretical background}

This section will give an overview of the two main concepts used for this research paper. First of all, it is about the knowledge transfer from teachers to students and in parallel the measurement of the perceived stress at the student's side.

\subsection{Knowledge transfer}

The aspect of knowledge transfer is embedded in the lager topic of knowledge management and very often combined with supporting IT systems. Knowledge Management is defined as "the facilitation and support of processes for creating, sustaining, sharing, and renewing of organizational knowledge in order to generate economic wealth, create value, or improve performance (Kong, 2003). Effective knowledge management for organizations is subsequently an indicator to reach competitive advantages and to tackle problems related to technology and permanent change (Lovrekovic, 2013). Especially the idea of change is important for our simulation scenario because the external requirements given by authorities leads to the need of permanent adaptation in any organization. The objectives of knowledge management include the enhancement and leverage of the company's knowledge assets in order to guarantee superior knowledge practices, better organizational behaviors and performance... (King, 2009). To shrink the explained need down to our lectures, the superior knowledge practice is important to teach students in a way that they have the skill advantages for their later jobs and positions.

Vat (2006) defines knowledge sharing as "a process of leveraging the collective individual learning of ... a group of people, to produce a higher-level organization-wide intellectual asset." Following this definition (Ortenblad, 2016; Tangaraja, 2016), knowledge sharing has the goal of improving the intellectual asset of every individual and the group as a whole. This describes exactly what the authors will reach with the lectures based on a competence-centered education, together with the BISE learning objectives. This will be the starting point for the planning of the curriculum for process management/quality management and governance. Therefore, the following learning objectives are defined in the curriculum: (1) process modeling, (2) process analysis and IT support, (3) process execution / governing the process and (4) process optimization / continuous improvement. The development of specific social and personal competence was not explicitly considered in the game design, but many of these competences were observed during the game.

\subsection{Cognitive load theory}

To secure the learning outcomes, it is important to take care of the perceived stress for students to get the right balance of challenge them but not overcharge them. Therefore, the authors will include the measurement of the whole case scenario based on the cognitive load theory, which was developed by John Sweller (1994). The theory provides a framework exploring the influence of the design of the case scenario and the learning outcomes, which goes further from the understanding then the external AACSB evaluation and the set criteria at MCI. The base idea that the human memory has limited capacity and it is bad for students if the experience given by the case overloads the capacity to process. In the next step, the knowledge transfer to the long-term memory is limited (Sweller, 1998; Miller, 1966; Van Merriënboer \& Sweller, 2010). This means that the development of the case scenario has to be carefully planned and divided into small chunks which do not lead to an overload of the learner and can be carefully charged, based on the learners need and speed. There are three different components which are defined in the theory of cognitive load: (1) intrinsic load, (2) extraneous load and (3) germane load.

Intrinsic load (1) reflects the inherent difficulty of the task and is given by the elements for a dedicated task. Processing this specific intrinsic load can be lessened by the learner's prior experience with this task (Sweller et. al., 1998) and would be different for the two described student groups - with and without practical experience. 
Extraneous load is described as the working memory consumed during task completion that is imposed on learners by the structure of the activity that does not enhance learning (Fraser et. al., 2015). In this component the lecturer has the most possible influence in decreasing extraneous load through tight tailoring of the case scenario and the content given. The intentional cognitive effort from the working memory dedicated to learning the particular new task and afterwards transferring the knowledge to the long-term memory is described by the germane load (Meguerdichian et. al., 2016). Especially by the division of the different knowledge nuggets transferred to the students with IT supported tools the overall stress at the student's side should be decreased.

All three mentioned components, describing the cognitive load, have to be summed up and should not be higher than the capacity of the working memory - otherwise learning is reduced. Based on these assumptions, the optimal design for the case scenario and the individual delivery of the knowledge nuggets avoids cognitive overload for the learners, maximizes germane load and minimizes extraneous load based on the individual ability to handle learning stress.

To measure the relative load on working memory in a case scenario, the NASA has developed a tool which will be used for the empirical part of this paper.

\section{Methodology}

The methodology used by the authors is two folded: The concept of the combination of the gamification aspects combined with a simulation game (presented in Ploder et. al. 2018) in this paper is combined with the IT supported knowledge nuggets delivery. The delivery of the knowledge nuggets is based on a self-evaluation (Klenowski, 1995) by every student to deliver the right nuggets to the right students needed and timed based on their needs. And after the knowledge sharing phase is over, the cognitive load has to be measured.

The self-evaluation of every student is based on an online questionnaire they can perform before lecture starts and this small questionnaire is delivered via our integrated LMS platform. The questions are asking about their working experience, their online education experience and their current knowledge about process management/quality management and governance with the aim to divide the students in two groups. From history we know that about half of the class still has experience or is working beside the university and the other half does not. For the later on implemented A-B testing this should be fine, that every group exists of enough students for statistical reasons. Usually students attend lectures relatively passively and find their motivation only in the final grade. That can lead to less commitment (Lei, 2010) and is a situation that should be tackled by this described way of studying and hopefully also the case study approach increases the engagement by implementing gamification and especially the idea of a playful design (Deterding et. al., 2011). The key factors which have to be implemented in every playful design are named as motivation and commitment, fun, competence enhancement in the specified area and practical applicability/sharing of knowledge.

For the measurement of the perceived cognitive load of the students, the NASA Task Load Index (NASA-TLX) (Hart 1986, Wayment 1995) is used. This is a very often applied and well standardized test which can be handled on paper with the paper and pencil package or in an online format. The NASA-TLX is based on six items, which have historically developed from nine items in the older "NASA Bipolar Rating Scale". Three dimensions relate to the demands imposed on the subject (mental, physical and temporal demands) and three dimensions to the interaction of the subject with the task (effort, frustration and performance) (Hart 2006). All the different items have to be weighted and the output of the whole measurement is an overall workload (OW) for every individual based on a particular knowledge chunk.

\section{The framework}

In this section the proposed framework of the authors is presented. There is lots of literature evidence (Ploder et al., 2018) combined with experience in the given topics regarding the implementation of the described simulation case. To increase the understanding of the framework figure 1 shows it in detail with all necessary steps which have to be performed.

The implementation of the whole idea is based on the well-known PDCA Cycle (also called Deming wheel) (Marquis, 2009). The framework describes all the necessary steps in every part of the framework in more detail. In the planning phase all the necessary knowledge nuggets have to be design and developed based on the curricua. Later they have to be assessed by the lecturers, the material has to be provided in the corresponding learning platform in logical order and based on the assessment marked with a "knowledge level" to be able to determine which student should get which knowledge nugget. The NASA-TLX questionnaire has to be prepared for the students - in our case we implemented that in 
the integrated LMS which helps to distribute the questionnaire based on the student's assessment about experience and later on compare the data for the two groups.

When lecture is starting, the two groups of students are fixed, and all the students can work on their own pace through the knowledge nuggets. They have to communicate with each other and some of the topics have to be handled in different teams. After every step in the case study (knowledge chunk completed) the cognitive load is tested. Therefore, it is necessary to find a balance of the time working on a knowledge nugget to not make them too small because this leads to a high amount of TLX measurements which will interrupt the lecture massively. So here the authors suggest to not go for more than two NASA-TLX measures within four hours - so that means roughly around four at maximum five measures during a whole day of lectures - this has to be taken into consideration when planning the length of the nuggets. All knowledge nuggets and the following measurement on individual base is supported by the integrated LMS and can be performed every time the students reach the next level.

Figure 1. Implementation Framework for Simulation Cases with NASA-TLX Measurement.

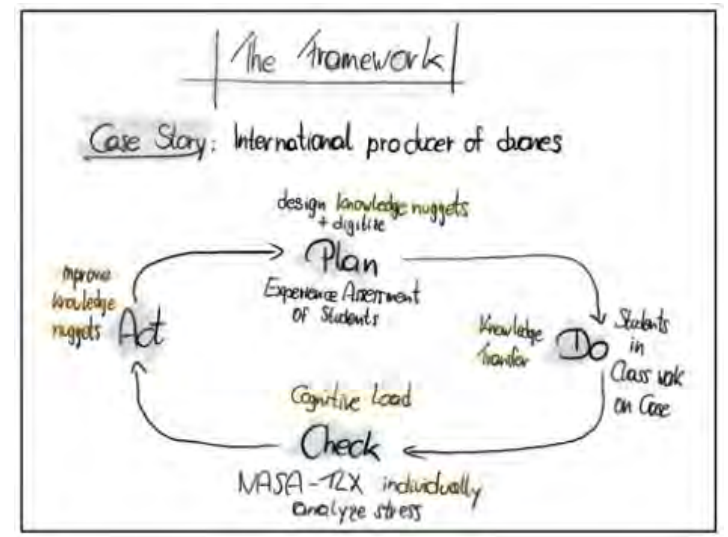

After the whole lecture is over, it is about the collection and analysis of the results. The two groups would be analyzed separated and later on the results of the individual and grouped OWs will be compared based on the handbook of the pencil and paper handbook of the NASA (Hart, 1986). The outcome of the two groups will first be combined and then look deeper into the individual stress levels and try to get as much feedback out of the analysis. To improve the whole system of the case, the integrated LMS, the evaluation and the individual knowledge nugget allocation for the next time has to be developed based on the learnings.

\section{Limitations and outlook}

The most obvious limitation of this paper lies the fact, that the first implementation will be done in June 2020 and so there are currently no empirical results available. But there are well documented results on the positive impact of gamification usage in case study teaching given (Ploder et. al., 2018). There is a strong impact on the measurement items which are externally required by our AACSB accreditation and this does not have to influence all universities - so the application would be especially useful for universities with AACSB accreditation teaching in the BISE area.

In future the initial implementation in the upcoming integrative synopsis in our master class be end of the term is the next step. A second improvement would be the implementation of an individual control loop for improved pre-selection of additional knowledge nuggets for the next case task based on the individual student's stress level.

\section{References}

Deterding S, Dixon D, Khaled R, Nacke L (2011) From game design elements to gamefulness. In: Proceedings of the 15th International Academic MindTrek Conference on Envisioning Future Media Environments - MindTrek '11:9

Fraser, K. L., Ayres, P., \& Sweller, J. (2015). Cognitive load theory for the design of medical simulations. Simulation in Healthcare, 10(5), 295-307.

Hart, S. G. (1986). NASA Task load Index (TLX). Volume 1.0; Paper and pencil package. 
Hart, S. G. (2006, October). NASA-task load index (NASA-TLX); 20 years later. In Proceedings of the human factors and ergonomics society annual meeting (Vol. 50, No. 9, pp. 904-908). Sage CA: Los Angeles, CA: Sage Publications

Jung R, Lehrer C (2017) Guidelines for Education in Business and Information Systems Engineering at Tertiary Institutions. Business \& Information Systems Engineering 59:189-203. doi: 10.1007/s12599-017-0473-5

King, W. R. (2009). Knowledge management and organizational learning. In Knowledge management and organizational learning (pp. 3-13). Springer, Boston, MA.

Klenowski, V. (1995). Student self-evaluation processes in student-centred teaching and learning contexts of Australia and England. Assessment in Education: Principles, Policy \& Practice, 2(2), 145-163.

Kong, E. (2003). The future of knowledge: Increasing prosperity through value networks: Verna Allee. Knowledge and Process Management, 10(2), 137.

Lei SA (2010) Intrinsic and extrinsic motivation: evaluating benefits and drawbacks from college instructors. Journal of Instructional Psychology 37:185+

Lovrekovic, Z. (2013). Why knowledge management?. Online Journal of Applied Knowledge Management (OJAKM), 1(2), 128-142.

Marquis, H. (2009). How to roll the Deming wheel. source: http://www. itsmsolutions. com/newsletters/DITYvol5iss28. pdf, 5.

Meguerdichian, M., Walker, K., \& Bajaj, K. (2016). Working memory is limited: improving knowledge transfer by optimising simulation through cognitive load theory. BMJ Simulation and Technology Enhanced Learning, 2(4), 131-138.

Miller, G. A. The magical number seven, plus or minus two: CR-564, pp. 94-125, 1966. some limits on our capacity for processing information. Psychol. [171 NV Zavalishin," Hypothesis concerning the distribution of eye Rev., vol. 63, pp. 81-97, 1956. fixation points during the examination of pictures," Automation.

Ortenblad, A. (2017). Handbook of Research on Knowledge Management Adaptation and Context. International Journal of Knowledge Management, 13(1).

Ploder, C., Bernsteiner, R., \& Schlögl, S. (2018, August). Improving Business Process Management Competencies by Applying Gamification Aspects in Teaching Bachelor Students. In International Workshop on Learning Technology for Education in Cloud (pp. 15-23). Springer, Cham.

Sweller, J. (1988). Cognitive load during problem solving: Effects on learning. Cognitive science, 12(2), 257-285.

Sweller, J. (1994). Cognitive load theory, learning difficulty, and instructional design. Learning and instruction, 4(4), 295-312.

Sweller, J., Van Merrienboer, J. J., \& Paas, F. G. (1998). Cognitive architecture and instructional design. Educational psychology review, 10(3), 251-296.

Tangaraja, G., Rasdi, R. M., Samah, B. A., \& Ismail, M. (2016). Knowledge sharing is knowledge transfer: a misconception in the literature. Journal of Knowledge Management.

Van Merriënboer, J. J., \& Sweller, J. (2010). Cognitive load theory in health professional education: design principles and strategies. Medical education, 44(1), 85-93.

Vat, K. H. (2006). IS design for community of practice's knowledge challenge. In Encyclopedia of Communities of Practice in Information and Knowledge Management (pp. 246-256). IGI Global.

Wayment, H. A., \& Taylor, S. E. (1995). Self-evaluation processes: Motives, information use, and self-esteem. Journal of personality, 63(4), 729-757. 